\title{
Médicos e filantropos \\ a institucionalização do ensino da pediatria e da assistência à infância no Rio de Janeiro da Primeira República*
}

\section{Physicians, philanthropists \\ and child care in Rio de Janeiro during the First Republic period}

\author{
GISELE SANGLARD \\ Doutora em história das ciências e da saúde (Fiocruz) \\ Fundação Oswaldo Cruz (Fiocruz) e Universidade Severino Sombra (USS) \\ Avenida Brasil, 4365 - sala 01 (Pavilhão Mourisco) - Manguinhos - 21045-900 \\ Rio de Janeiro - Brasil \\ sanglard@coc.fiocruz.br
}

LUIZ OTÁVIO FERREIRA

Doutor em história social (USP)

Fundação Oswaldo Cruz (Fiocruz) e Universidade do Estado do Rio de Janeiro (Uerj)

Avenida Brasil, 4036 - sala 408 - Manguinhos - 21040-361

Rio de Janeiro - Brasil

lotavio@fiocruz.br

RESUMO Com o objetivo de estudar a constituição da assistência pública à infância e do ensino da pediatria no Rio de Janeiro, partimos da hipótese de que o ensino da pediatria ocorreu ao largo da Faculdade de Medicina do Rio de Janeiro. Os médicos envolvidos nesse processo criaram espaços independentes, tanto para a clínica quanto para o ensino das chamadas moléstias de crianças. Acompanhamos a trajetória de dois desses médicos,

* Artigo recebido em: 18/09/2010. Aprovado em: 24 de setembro de 2010. 
Antônio Fernandes Figueira e Luiz Barbosa, que têm em comum a militância pelo ensino da pediatria e a liderança exercida à frente de instituições filantrópicas voltadas para o cuidado das crianças pobres. Consideramos a filantropia uma característica da sociedade de elite da Primeira República, essencial às questões políticas e acadêmicas envolvidas no processo de institucionalização da pediatria e da assistência pública à infância.

Palavras-chave filantropia, medicina, assistência à infância

ABSTRACT This article aims to study the constitution of public childcare and the teaching of pediatrics in Rio de Janeiro. We are based on the hypothesis that the teaching of pediatrics occurred alongside The University of Medicine of Rio de Janeiro. Physicians involved in this process created independent centers for their clinics as well as for the teaching of the so-called children's maladies. We have accompanied the story of two doctors involved in this process, Antônio Fernandes Figueira and Luiz Barbosa. What they have in common is their fight for the teaching of pediatrics, and their leadership in philanthropic institutions related to childcare for the poor. We consider philanthropy as a key characteristic of High-class society during the First Republic, because it was vital for political and academic issues involved in the institutionalization process of pediatrics and public childcare.

Keywords philanthropy, Medicine, childcare

\section{Sociedade e Assistência na Primeira República}

A Primeira República é período de grande efervescência na vida cultural da cidade do Rio de Janeiro. Literatos como Lima Barreto, João do Rio e Luiz Edmundo ${ }^{1}$ imortalizaram em suas crônicas o período, seus personagens e seus hábitos. Historiadores como Nicolau Sevcenko, Jeffrey Needell e Rosa Araújo² pensaram as várias facetas da cultura e da sociedade daquela época.

Trabalhos recentes ${ }^{3}$ apontam outra característica desse tempo, além das já indicadas vida frenética, velocidade, prazeres, boemia, coleção, o trajar, a arquitetura, participação em clubes de sociabilidade, etc.: a filantropia, que

1 BARRETO, Lima. Contos reunidos. Rio de Janeiro: Garnier, 1990; RIO, João do. A alma encantadora das ruas. São Paulo: Companhia das Letras, 1997; EDMUNDO, L. O Rio de Janeiro do meu tempo. $4^{\text {aed. }}$ Rio de Janeiro: Conquista, 1957, 4.v.

2 SEVCENKO, Nicolau. Literatura como missão: tensões sociais e criação cultural na Primeira República. $4^{a} e d$. São Paulo: Editora Brasiliense, 1999; NEEDELL, Jeffrey. D. Belle époque tropical: sociedade e cultura de elite no Rio de Janeiro na virada do século. São Paulo: Companhia das Letras, 1993; ARAÚJO, Rosa. Maria Barboza de. A vocação do prazer: a cidade e a família no Rio de Janeiro republicano. Rio de Janeiro: Rocco, 1995.

3 SANGLARD, Gisele. Entre os salões e o laboratório: Guilherme Guinle, a saúde e a ciência no Rio de Janeiro. Rio de Janeiro: Editora Fiocruz, 2008. Col. História \& Saúde; SANGLARD, Gisele. Laços de sociabilidade. História, Ciências, Saúde - Manguinhos, Rio de Janeiro, v.17, supl.1, p.127-148, jullho 2010. 
desponta como relevante elemento para o entendimento do período não só pelo caráter de utilidade social que the é atribuído desde o surgimento desse neologismo no Século das Luzes, ${ }^{4}$ mas também por incorporar, muitas vezes, as questões do mundo do trabalho, ${ }^{5}$ ao mesmo tempo em que ressalta outra característica do período: as reuniões sociais - os chás beneficentes ou mesmo os encontros sociais, muitos deles guardando ainda a referência das reuniões savantes, de sociabilidade. ${ }^{6}$

Percebe-se assim que uma parcela da elite carioca dirigia seu capital social, político e financeiro para a abertura de hospitais na cidade do Rio de Janeiro voltados para o atendimento aos pobres. ${ }^{7}$ Nesse cenário, algumas questões sobressaem: o projeto político de construção nacional que estava sendo discutido e construído no período; o discurso médico, tanto no que tange à questão saúde/doença quanto na defesa de sua profissionalização (novas especialidades surgindo, disputas profissionais, a nova relação médico/paciente, entre outras questões); e a própria cultura de elite que se estava constituindo nesse período, sobretudo durante a belle époque. É nesse momento que a filantropia desponta como ação típica da elite, afastando-se da dimensão nitidamente caritativa que pautou suas ações até o século XIX.

Interessa-nos neste momento o encontro de discurso médico e ação de um grupo da sociedade, que defendia um determinado projeto de nação e encontrava no discurso médico uma das formas de alcançá-lo.

Nos cerca de 40 anos que caracterizam a Primeira República brasileira foram vários os exemplos de ações filantrópicas voltadas para a saúde na cidade: a criação do Instituto de Proteção e Assistência à Infância - Ipai (1899); da Policlínica de Botafogo (1899); da Liga Brasileira contra a Tuberculose (1900); da Policlínica das Crianças (1909) e do Hospital São Zaccharias (1914), ambos pela Misericórdia carioca; as ações de Guilherme Guinle na criação do Hospital Gaffrée e Guinle (1924-1929) e do Hospital e Instituto do Câncer (1927-1936); entre outras. Todas essas iniciativas apontam para uma nova relação entre a elite carioca e a saúde.

Esse período é também caracterizado como o momento de transição de assistência eminentemente centrada nas ações das Misericórdias para

4 Catherine Duprat chama atenção para o fato de que, ao surgir o neologismo filantropia durante o Século das Luzes, uma das traduções possíveis era justamente sociabilidade, termo que, entretanto, não vingou. Ver: DUPRAT, Catherine. Pour l'amour de l'humanite. Le temps des philantropes: la philantropie parisienne des Lumières à la monarchie de Julliet. Paris: Éditions CTHS, 1993, t.1.

5 SANGLARD, Gisele. Laços de sociabilidade filantropia e o Hospital do Câncer do Rio de Janeiro (1922-1936): VISCARDI, Claúdia Maria Ribeiro. Estratégias populares de sobrevivência: o mutualismo no Rio de Janeiro republicano. Revista Brasileira de História, São Paulo, v.29, n.58, p.291-316, dezembro de 2004.

6 SANGLARD, Gisele. Entre os salões e o laboratório: Guilherme Guinle, a saúde e a ciência no Rio de Janeiro.

7 SANGLARD, Gisele. A Primeira República e a constituição de uma rede hospitalar no Rio de Janeiro. In: PORTO Ângela et allli. (orgs.) História da saúde no Rio de Janeiro: instituições e patrimônio arquitetônico. Rio de Janeiro (1808-1958). Rio de Janeiro: Editora Fiocruz, 2008. 
ampliação das ações do Estado na assistência hospitalar. ${ }^{8}$ Maria Luiza Marcílio, ${ }^{9}$ em seu livro sobre a criança abandonada, chama atenção para o processo em que o Estado começa a "intervir no trabalho das Misericórdias, procurando transformá-las em institutos de proteção à infância abandonada a serviço do poder público. Em outras palavras, procurou-se esvaziar o caráter caritativo de sua assistência". A autora ressalta, sobretudo, o papel dos médicos higienistas na questão da infância a partir de diversas frentes de intervenção, tais como mortalidade infantil, educação de mães e cuidado com corpo e mente, no que tange às doenças infantis, tanto nos aspectos de saúde quanto nos estudos. Ou, como Gilberto Freyre qualificou o higienismo: "messiânico", redentor e fundador. ${ }^{10}$

Neste artigo analisamos o encontro de projetos de médicos e de filantropos. Estaremos nos ocupando das relações estabelecidas entre dois dos "pais fundadores" da pediatria brasileira, Luiz Barbosa e Antônio Fernandes Figueira, e membros destacados da elite republicana carioca representados pela família Guinle e o empresário José Carlos Rodrigues.

\section{Pediatria, Assistência à Infância e o Ensino Médico}

Atribui-se a criação da cadeira de clínica e policlínica médica e cirúrgica na Faculdade de Medicina do Rio de Janeiro (FMRJ) à iniciativa do médico carioca Carlos Arthur Moncorvo de Figueiredo (1846-1901) que, em 1882, apresentou ao então ministro dos Negócios do Império Rodolfo Dantas texto intitulado Rápida indicação dos motivos que justificam a criação nas faculdades de medicina brasileiras de uma cadeira de clínica de moléstias de crianças. ${ }^{11}$

O argumento de Moncorvo de Figueiredo para justificar a criação dessa cadeira apoiava-se em duas concepções típicas do pensamento médico brasileiro da segunda metade do século XIX.12 A primeira era pertinente ao tema das "condições especiais de nosso clima" que, exercendo intensa influência sobre a etiologia das doenças, tornaria extremamente singular o quadro da patogenia local, afetando especialmente a infância. A segunda relacionava-se à "ignorância dos mais elementares princípios de higiene popular", descuido responsável pela mortalidade infantil que atingia, sobretudo em meio à classe pobre do Rio de Janeiro, índices alarmantes "na

8 SANGLARD, Gisele. A Primeira República e a constituição de uma rede hospitalar no Rio de Janeiro.

9 MARCÍLIO, Maria Luiza. História social da criança abandonada. 2. ed. São Paulo: Hucitec, 2006, p.195.

10 FREYRE, Gilberto. Ordem e progresso. Rio de Janeiro: Record, 2000.

11 O texto de Moncorvo de Figueiredo foi integralmente reproduzido em FIGUEIREDO, Arthur Moncorvo de. Rápida indicação dos motivos que justificam a criação nas faculdades de medicina brasileiras de uma cadeira de clínica de moléstias de crianças. Apud: ROCHA, José Martinho da. Introdução à história da puericultura e pediatria no Brasil (1500-1882). Rio de Janeiro: Produtos Nestlé, 1947, p.53-61.

12 FERREIRA, Luiz Otávio. Uma interpretação higienista do Brasil imperial. In: HEIZER, Alda e VIDEIRA, Antônio Augusto Passos. (orgs.) Ciência, civilização e impérios nos trópicos. Rio de Janeiro: Access Editora, 2001, p.207-223. 
razão de 460 por 1.000 , incluindo os nascidos mortos, ou de 410 por 1.000 até a idade de sete anos". ${ }^{13}$

Reconhecida a complexidade etiológica e a gravidade social do problema da infância, a implantação de uma cadeira dedicada ao estudo e ao tratamento das moléstias de crianças esbarrava em um obstáculo de natureza institucional. Segundo Moncorvo de Figueiredo, a principal dificuldade para efetivação do ensino da pediatria estava na precariedade da "acanhada enfermaria" existente no Hospital da Misericórdia na qual deveriam ser desenvolvidas as atividades práticas da futura cadeira.

Essa pequena enfermaria do Hospital da Misericórdia não pode se prestar ao ensino da clínica em questão, porque a concorrência a ela é por demais medíocre e pouco variada. Para isto contribuem os usos e costumes de nossa população pobre, que apesar de suas precárias condições financeiras, multiplica os fracos recursos disponíveis, recorre à caridade alheia, e encontra sempre o auxílio que Ihe permita a conservação no domicílio do filho doente e apenas apresentá-lo à consulta, quando muito, de um facultativo. ${ }^{14}$

Para que a cadeira de moléstias de crianças pudesse funcionar, era necessário haver um fluxo de pacientes infantis em número e em diversidade patológica ampla o suficiente para fornecer casos que pudessem ser assistidos e estudados pelos professores e alunos. Esse não era um problema de fácil solução, pois como observava o próprio Moncorvo de Figueiredo, ele envolvia o costume compartilhado entre a população pobre da cidade do Rio de Janeiro de cuidar das doenças de suas crianças em casa, com a ajuda dos próprios familiares ou vizinhos, e raramente encaminhá-las ao médico.

Moncorvo de Figueiredo também lembrava os "conhecidos e inquebrantáveis óbices opostos pela congregação religiosa das irmãs de caridade"15 a qualquer tentativa de se instituir um curso de clínica nas dependências das enfermarias da Santa Casa. A subordinação à Santa Casa de Misericórdia também impediria que a Casa dos Expostos ${ }^{16}$ fosse aproveitada para fins acadêmicos e científicos, a exemplo do recurso adotado na França, em 1879, quando o Hôpital des Enfants Assistés foi transformado em espaço oficial de estudos e ensino das moléstias de crianças da Faculdade de Medicina de Paris. Não podendo fazer-se o mesmo com a Casa dos Expostos do Rio de Janeiro, lamentava-se que assim se desperdiçava

13 FIGUEIREDO, Carlos Arthur Moncorvo de. Rápida indicação dos motivos..., p.54

14 FIGUEIREDO, Carlos Arthur Moncorvo de. Rápida indicação..., p.56.

15 FIGUEIREDO, Carlos Arthur Moncorvo de. Rápida indicação..., p.56.

16 VENÂNCIO, Renato Pinto. Famílias abandonadas. Assistência à criança de camadas populares no Rio de Janeiro e em Salvador - séculos XVIII e XIX. Campinas: Papirus. 1999. 
esse rico manancial da patologia dos recém-nascidos, no qual importantes pesquisas poder-se-iam fazer sobre o caráter especial impresso pelas novas condições climáticas à marcha e terminação de um grande número de moléstias peculiares a esse período de vida, essa copiosa fonte de instrução clínica sempre esteve, entretanto, e ainda está escrupulosamente vedada ao olhos profanos, que nem sempre lobrigam o que aí se passa além do limiar. ${ }^{17}$

Da maneira como Moncorvo de Figueiredo vai expondo seus argumentos, fica evidente que a implantação da cadeira de moléstia de crianças esbarrava na tensa relação entre a FMRJ e a Santa Casa de Misericórdia no que tange ao papel desempenhado pelo hospital mantido pela irmandade na prestação de assistência à saúde e no desenvolvimento do ensino médico. A institucionalização da pediatria (e de outras especialidades médicas emergentes no mesmo período) apontava para uma redefinição do modelo de assistência à saúde vigente no Brasil, que combinava conhecimentos e práticas da medicina e valores e preceitos da caridade cristã (católica). Um dos problemas desse convênio era a supremacia exercida pelos membros leigos e religiosos da Irmandade da Misericórdia na administração e no controle dos ambientes hospitalares. Para tornar viáveis as inovações propiciadas pela intensa especialização da medicina do final do século XIX, como o caso da pediatria, era fundamental assegurar a laicização da assistência à saúde, atestando mais autonomia ou mesmo a supremacia aos médicos nesse campo da ação social.

Se a enfermaria instalada no Hospital da Santa Casa de Misericórdia e a Casa dos Expostos eram espaços inapropriados ou vedados ao acesso de médicos e estudantes, restaria ter um modelo institucional alternativo para a instalação da cadeira de moléstias de crianças na FMRJ. Esse modelo era o da "policlínica ou dos dispensários". Segundo Moncorvo de Figueiredo, a policlínica era instalação de saúde destinada ao tratamento de doentes que não se recolhem ao hospital, os quais, permanecendo em seus domicílios, no seio da família, vão à consulta e recebem os medicamentos prescritos. $\mathrm{Na}$ época eram duas as instituições modelares desse novo gênero de prestação de assistência à saúde da infância que se combinava ao desenvolvimento de estudos científicos e ao treinamento clínico de estudantes: a Policlínica de Montpellier e a Policlínica de Havre, ambas na França. O modelo das policlínicas surgia como alternativa ao tratamento de crianças em hospitais, medida que era crescentemente condenada pelos pediatras, sob a alegação de que essa prática, além promiscuir os pacientes infantis misturando-os aos adultos, também expunha as crianças ao "perigo do contágio de muitas moléstias" e à "dura separação das crianças do seio materno". ${ }^{18}$

17 FIGUEIREDO, Carlos Arthur Moncorvo de. Rápida indicação..., p.57.

18 FIGUEIREDO, Carlos Arthur Moncorvo de. Rápida indicação..., p.59. 
No caso da implantação da cadeira de moléstias de crianças na FMRJ, a solução oferecida por Moncorvo de Figueiredo ao governo imperial foi à utilização, "sem ônus" da Policlínica Geral do Rio de Janeiro, instituição criada e dirigida pelo ele próprio em 1881.

Ora, encontrando o governo imperial já organizada e instalada, sem ônus, para o Estado, a 'Policlínica Geral do Rio de Janeiro', da qual faz parte a Clinica das Crianças, poderia, instituindo nela o ensino desta, preencher sem maior dispêndio uma grave lacuna ainda existente no programa do ensino das nossas faculdades de medicina e que urge reparar. ${ }^{19}$

A ideia de Moncorvo de Figueiredo era não submeter o ensino de moléstias de crianças à tutela do Hospital da Santa Casa de Misericórdia, seguindo, como ele próprio sugere, a solução adotada no caso da clínica de partos que foi instalada na Casa de Saúde de Nossa Senhora da Ajuda, em que existia um serviço de maternidade sob a condução da parteira diplomada madame Durochet ${ }^{20}$ e do cirurgião Luiz da Cunha Feijó, antigo professor da cadeira de partos. Contudo, não devemos esquecer que a Casa de Saúde de Nossa Senhora da Ajuda tinha relações muito próximas com a FMRJ, mantendo entre seus médicos e cirurgiões consultantes vários catedráticos, como Manuel Valadão Pimentel, João Vicente Torres Homem e Francisco Praxedes de Andrade Pertence, entre outros. ${ }^{21}$ Mesmo contando como o apoio do imperador Pedro Il e da imperatriz dona Tereza Cristina e, tal qual a Santa Casa de Misericórdia, promover o atendimento gratuito à população carente, a Policlínica Geral do Rio de Janeiro não mantinha com a FMRJ relação de parceria envolvendo o ensino médico.

Embora estivesse tecnicamente habilitado para a função em decorrência dos estágios feitos em serviços pediátricos europeus (França) entre os anos de 1872 e 1874, Moncorvo de Figueiredo não foi escolhido para ocupar a cátedra de clínica e policlínica médica e cirúrgica de crianças, criada em 1883. Supomos que sua participação ativa no movimento pela reforma das faculdades de medicina, ressaltada pela publicação, em 1874, do folheto intitulado Do exercício e ensino da medicina no Brasil, tenha sido um dos motivos que levaram à rejeição de seu nome. No libelo, Moncorvo de Figueiredo criticava duramente os métodos de ensino vigentes nas faculdades e defendia, entre outras ideias, a liberdade de ensino em contraposição à rigidez e à vitaliciedade das cátedras e à instalação de um "hospital de clínicas" da faculdade sem vínculos com o Hospital da Santa Casa de Misericórdia.

19 FIGUEIREDO, Carlos Arthur Moncorvo de. Rápida indicação..., p.60.

20 Ver MOTT, Maria Lúcia de Barros. Madame Durocher, modista e parteira. Revista Estudos Feministas, Rio de Janeiro, v.2, n.1, p.101-116, 1994.

21 ARAÚJO, Achilles Ribeiro de. A assistência médica hospitalar no Rio de Janeiro no século XIX. Rio de Janeiro: Ministério da Educação e Cultura/Conselho Federal de Cultura, 1982, p.149-154. 
A reforma do ensino médico decretada em abril de 1879 pelo ministro do Império Leôncio de Carvalho atendeu e ao mesmo tempo frustrou as aspirações de Moncorvo de Figueiredo. A reforma instituiu a frequência livre às aulas e sabatinas, medida que logo se mostrou desastrosa e foi por isso abolida, em 1883, pelo novo diretor da FMRJ, Vicente Candido Figueira Sabóia, que tornou obrigatória a frequência aos trabalhos práticos e laboratórios. Também foi instituída liberdade de ensino, com a permissão para a realização de cursos não oficiais de matérias do currículo nas instalações da própria faculdade. Na prática, essa medida, permitiu a realização de cursos livres para além dos muros da FMRJ, como foi o caso das aulas sobre doenças de crianças oferecidas com regularidade na Policlínica Geral da Cidade do Rio de Janeiro por Moncorvo de Figueiredo desde 1881 até 1901, ano de sua morte.

As disposições da Reforma Leôncio de Carvalho, que ainda não haviam sido executadas, foram ampliadas pelos decretos de 12 de março de 1881 e de 30 de outubro de 1882, e postas em execução por ordem dos ministros do Império Rodolfo Epifanio de Souza Dantas e Pedro Leão Veloso. São criadas sete novas cátedras: clínica obstétrica e ginecológica, clínica psiquiátrica, clínica oftalmológica, clínica das moléstias médicas e cirúrgicas de crianças, anatomia e fisiologia patológicas, clínica de moléstias e doenças cutâneas e sifilíticas, segunda cadeira de clínica médica de adultos e segunda cadeira de clínica cirúrgica de adultos. Os concursos para o preenchimento das novas cadeiras ocorreram em 1883. Com a criação dessas cátedras inaugura-se fase de grande atividade institucional, social e cívica por parte dos novos especialistas (obstetras, psiquiatras, dermatologistas e pediatras), movimento que resultará na criação de novas entidades e instituições médicas, todas elas engajadas em causas de cunho nacionalista, filantrópico e higienista. ${ }^{22}$

Ao que consta, a nomeação de Moncorvo de Figueiredo para a cátedra de clinica de moléstias médicas e cirúrgicas de crianças já estava acertada com o ministro Souza Dantas, que estaria de acordo com a indicação sem necessidade de concurso. ${ }^{23}$ Parece, contudo, que outros interesses clientelísticos e laços regionais impuseram a realização de concurso, do qual Moncorvo de Figueiredo não quis participar por se considerar hors concours na especialidade pediátrica. O primeiro catedrático de clínica de moléstias médicas e cirúrgicas de crianças foi o médico baiano Candido Barata Ribeiro (1843-1910) que se notabilizou mais pela atividade política como republicano histórico e pelos cargos de prefeito do Distrito Federal,

22 Ver, por exemplo, COSTA, Jurandir Freire. História da psiquiatria no Brasil: um corte ideológico. $4^{a}$ ed. Rio de Janeiro: Xenon Editora, 1989; CARRARA, Sérgio. Tributo a Vênus: a luta contra a sífilis no Brasil da passagem do século aos anos 20. Rio de Janeiro: Editora Fiocruz, 1996; FREIRE, Maria Martha de Luna. Mulheres, mães e médicos: discurso maternalista no Brasil. Rio de Janeiro: FGV/UFFRJ, 2009.

23 ROCHA, José Martinho da. Introdução à história da puericultura e pediatria no Brasil (1500-1882), p.62. 
senador da República e ministro do Supremo Tribunal Federal, do que pelo desempenho como professor e clínico especializado em pediatria.

As consequências da rejeição de Moncorvo de Figueiredo pela FMRJ são lembradas em vários relatos sobre a história do ensino da pediatria no Rio de Janeiro. Em 1912, Luiz Barbosa - futuro catedrático de pediatria em 1928 - recordava que, até 1895, o ensino da pediatria não estava efetivado "sendo os alunos anualmente dispensados de frequência e de exame na especialidade" e que só 14 anos após a criação da cátedra é que "registramos nos arquivos oficiais o primeiro termo de habilitação acadêmica pediátrica". O caráter misto imposto à disciplina, que não separava o "ensino da medicina e da cirurgia, da ortopedia e da higiene infantil", tornava o ensino da pediatria ainda mais confuso. ${ }^{24}$ Além disso, os cursos de pediatria na FMRJ continuavam sendo ministrados na mesma precária enfermaria do Hospital da Santa Casa de Misericórdia, que já havia sido considerada inadequada por Moncorvo de Figueiredo em 1881.

Em 1910, quando faleceu Barata Ribeiro, o ensino e a prática da pediatria se desenvolviam à margem da FMRJ e do Hospital da Santa Casa de Misericórdia. Efetivamente, a pediatria institucionalizava-se em clínicas, dispensários, enfermarias, lactários e creches de entidades privadas que adotavam o modelo médico-filantrópico pioneiramente implantado na Policlínica Geral do Rio de Janeiro. Essas instituições eram o Instituto de Proteção e Assistência à Infância - Ipai, a Policlínica de Botafogo e a Policlínica das Crianças vinculada à Santa Casa de Misericórdia.

\section{As disputas pela cátedra de pediatria}

A conturbada trajetória da cadeira de pediatria da FMRJ, porém, ainda não estava encerrada. Com a morte de Barata Ribeiro ascendia temporariamente ao cargo Francisco Simões Corrêa (1848-1930). Formado em 1876 na FMRJ com tese sobre a febre amarela, Simões Corrêa participou ativamente das campanhas de combate às epidemias empreendidas naquela década. Foi estudante ligado a dois dos mais importantes professores da FMRJ - foi interno de clínica cirúrgica dirigida pelo visconde de Sabóia e de clínica médica regida por Torres Homem - o que deve ter influído em sua nomeação, em 1891, para o posto de professor substituto da cadeira de clínica e policlínica médica e cirúrgica das crianças. No Rio de Janeiro fundou e dirigiu até sua morte a Casa de Saúde São Sebastião. Também esteve à frente de vários periódicos médicos: Imprensa Médica, Archivos de Medicina e Revista Médico Cirúrgica. Foi presidente honorário da Sociedade de Medicina e Cirurgia do Rio de Janeiro, sociedade médica

24 BARBOSA, L. Clinica de crianças: conferência inaugural. Rio de Janeiro: Besnard, 1914, p.16. 
criada em 1888 que durante os primeiros anos da República rivalizava com a Academia Nacional de Medicina. ${ }^{25}$

Logo após assumir interinamente a cátedra, Simões Corrêa empenhouse em conseguir a aprovação oficial para desdobramento da cadeira, o que resultou na criação de duas cátedras de pediatria: clínica de pediatria médica e higiene infantil, e clínica cirúrgica infantil e ortopédica, divisão autorizada pela Lei Orgânica do Ensino Superior e do Fundamental, proposta em 1911 pelo ministro do Interior Rivadávia da Cunha Corrêa. ${ }^{26}$

A mesma lei recriava a figura do professor livre-docente, inspirada no regime universitário alemão. Por esse dispositivo, depois de ter um trabalho original aprovado pela congregação de uma escola superior, um graduado, por exemplo, de medicina, poderia ministrar cursos pelos quais seria remunerado apenas pela taxas recebidas dos alunos, descontadas as despesas e o percentual devido à instituição. Durante toda a década de 1910 o ensino da pediatria foi desenvolvido em cursos oferecidos por professores livres-docentes sendo uns dos mais famosos os ministrados pelo já citado Luiz Barbosa.

Aberto o concurso para o preenchimento da vaga de professor substituto inscreveram-se dois médicos discípulos de Moncorvo de Figueiredo: Luiz do Nascimento Gurgel (1890-1928) e Antonio Fernandes Figueira (1863-1928).

A trajetória acadêmica e profissional de Nascimento Gurgel é marcada pelos vínculos que manteve com Moncorvo de Figueiredo e com seu filho, Carlos Arthur Moncorvo Filho (1871-1944), fundador do Instituto de Proteção e Assistência à Infância do Rio de Janeiro - Ipai, entidade que a partir de 1901 se tornaria um paradigma da ação filantrópica e higienista responsável pela introdução de inúmeras inovações no âmbito das práticas assistenciais. ${ }^{27}$ Durante 10 anos, Nascimento Gurgel foi adjunto de Moncorvo de Figueiredo na Policlínica Geral do Rio de Janeiro e, de 1901 a 1906 - ano em deixou a entidade -, chefe do consultório de crianças do Ipai. Em 1910, candidatou-se à vaga de professor substituto da nona seção da FMRJ (pediatria), ocupada desde 1895 por Francisco Simões Corrêa.

Outro candidato concorria à vaga: Antonio Fernandes Figueira, médico formado pela FMRJ em 1887. Ainda quando estudante Fernandes Figueira frequentou os cursos livres de pediatria ministrados por Moncorvo de Figueiredo na Policlínica Geral do Rio de Janeiro e foi assistente de Barata

25 BATISTA, V. Professor Dr. Francisco Simões Corrêa. Pediatria Prática. Revista mensal de clinica infantil e puericultura, v.ll, fasc.XI, p.393-394, abril 1930

26 CUNHA, Luiz Antônio. A universidade temporã: o ensino superior da Colônia à Era Vargas. Rio de Janeiro. Editora Civilização Brasileira/Edições UFC, 1980, p.163.

27 WADSWORTH, James E. Moncorvo Filho e o problema da infância: modelos institucionais e ideológicos de assistência à infância no Brasil. Revista Brasileira de História, São Paulo, v.19, n.37, p.103-124, 1999. 
Ribeiro, titular da clínica de pediatria na FMRJ. ${ }^{28}$ A descrição da trajetória profissional e acadêmica de Fernandes Figueira exige cuidado por parte do historiador. Sua biografia, elaborada por colegas de especialidade e confrades das associações científicas e literárias as quais pertenceu, ${ }^{29}$ é cercada de alusões a supostas injustiças que Ihe foram dirigidas ou de críticas veladas a sua personalidade retraída e a sua vaidade intelectual. ${ }^{30} \mathrm{Apesar}$ dos reconhecidos méritos científicos, ${ }^{31}$ sua trajetória como médico e homem público foi marcada por controvérsias relacionadas às lutas institucionais e às disputas pessoais com colegas de profissão. O epicentro dessas lutas e disputas era o concurso para a vaga de substituto da cadeira de clínica e policlínica médica e cirúrgica das crianças, ocorrido em 1910.

Na ocasião da realização do concurso Fernandes Figueira já possuía notoriedade científica e clínica decorrente da repercussão nacional e, sobretudo, da consagração internacional de seu livro Elementos de semiologia infantil, publicado em 1903. O livro foi traduzido para o francês, com prefácio do pediatra Victor Henri Hutiel (1849-1933), diretor do Hôpital des Enfants-Malades de Paris, e também para o italiano. A Academia Nacional de Medicina que, em 1895, já havia distinguido Fernandes Figueira com o prêmio Visconde de Alvarenga pelo trabalho Diagnóstico das cardiopatias infantis, também reconheceu o valor científico de Elementos de semiologia infantil e provavelmente foi por recomendação da academia que o Congresso Nacional lhe concedeu como prêmio a restituição das despesas feitas com a edição do livro. Na ocasião do concurso a obra científica de Fernandes Figueira já era razoavelmente extensa. Um biógrafo cita 18 trabalhos publicados até 1910, ${ }^{32}$ mas só em Brasil Médico, periódico vinculado à Policlínica Geral do Rio de Janeiro, contabilizamos entre 1888 e 1910 pelo menos 30 artigos seus.

Além da produção científica, Fernandes Figueira também possuía sólida e diversificada experiência clínica. Por indicação de Oswaldo Cruz, então à frente da Diretoria Geral de Saúde Pública (DGSP), entre 1900 e 1910 foi chefe da enfermaria de crianças do Hospital São Sebastião, tendo sido o responsável por introduziu naquele hospital a prática de as crianças

28 BARBOSA, L. Fernandes Figueira na pediatria brasileira. Pediatria Prática. Revista mensal de clínica infantil e puericultura, v.I, fasc.XI, p.43-45, abril 1928.

29 Fernandes Figueira pertenceu às mais prestigiosas academias nacionais, tendo sido eleito, em 28 de julho de 1903, para a Academia Nacional de Medicina, da qual chegou a ser presidente, e em 28 de junho de 1915 para o IHGB.

30 Dentre os biógrafos destacamos LEITE, S. Sessão em homenagem à memória do sócio efetivo Sr. Antônio Fernandes Figueira, realizada em 13 de junho de 1928 (conferência do sr. Selidônio Leite). Revista do Instituto Histórico e Geográfico Brasileiro, t.104, v.158, p.844-866, 1929; BARBOSA, L. Fernandes Figueira na pediatria brasileira, p.43-45; PRADO, C. Fernandes Figueira. Pediatria Prática. Revista mensal de clínica infantil e puericultura, v.l, fasc. XI, p.37-41, abril 1928.

31 Sobre a contribuição científica de Fernandes Figueira os relatos mais equilibrados são GESTEIRA, Martagão. Lição inaugural da clínica de pediatria médica da Bahia, 1928. Pediatria Prática. Revista mensal de clínica infantil e puericultura, v.I, fasc.VI, p.243-252, agosto 1928; SODRÉ, F. A contribuição neurológica de Fernandes Figueira. Brasil-Médico, ano XLII, n.16, p.417-420, abril 1928.

32 PRADO, C. Fernandes Figueira, p.37-41. 
serem internadas na companhia de suas mães. Foi contratado por Juliano Moreira como médico responsável pelo Pavilhão Bourneville, enfermaria que cuidava do tratamento e educação das crianças "anormais ou com atrasos", no Hospício Nacional dos Alienados. ${ }^{33}$ Em 1909, foi convidado a assumir a direção do Hospital de Crianças da Santa Casa de Misericórdia, o primeiro do gênero no Brasil, cuja construção, num terreno no bairro de São Cristovão, fora patrocinada pelo empresário e filantropo José Carlos Rodrigues.

Portador de respeitável credencial científica, Fernandes Figueira teria "repetido o gesto" de seu mestre Moncorvo de Figueiredo ao pleitear a cátedra sem necessidade de submeter-se ao concurso. Segundo o relato de Luiz Barboza, Fernandes Figueira, "apoiando-se em pareceres das maiores sumidades européias pretendeu, em 1910, ser dispensado do concurso para professor substituto da nona seção, em cuja posse pretendia entrar apenas com o valor intrínseco de sua produção didática". ${ }^{34} \mathrm{O}$ desfecho foi totalmente desfavorável a Fernandes Figueira, que, não obtendo o apoio da maioria da congregação da FMRJ, viu-se obrigado a cancelar sua participação no concurso.

Com a desistência de Fernandes Figueira, Nascimento Gurgel tornouse candidato único e, aprovado, logo se aliou a Simões Correa, catedrático interino, no pleito para que fossem separadas as partes médicas e cirúrgicas da cadeira. A Lei Rivadávia Corrêa de 1911 autorizou o desdobramento da cátedra em duas. Com isso Nascimento Gurgel ascendeu à condição de catedrático. No entanto, contrariando sua expectativa não foi nomeado para a cadeira de clínica de pediatria médica e de higiene infantil, mas para a de clínica cirúrgica infantil e ortopédica, para a qual não estava preparado. Segundo um de seus biógrafos, "mesmo assim sem aparelhamento e sem instalações, fazendo apenas a cirurgia falada" dedicou-se ao magistério "dentro das possibilidades técnicas de que dispunha". ${ }^{35}$ Repetindo costume cultivado pelos professores da FMRJ, Nascimento Gurgel empreendeu, logo depois de sua posse na cadeira, longa viagem de estudos à Europa, onde frequentou clínicas infantis e institutos ortopédicos. Em 1925, com a aposentadoria de Francisco Simões Corrêa, foi transferido para a clínica de pediatria médica e higiene infantil. À frente da cátedra instalou no Hospital São Francisco de Assis um ambulatório e enfermaria especializada para onde transferiu o ensino. Seu tempo de permanência no comando da cadeira foi, entretanto, relativamente curto. Nascimento Gurgel faleceu

33 SILVA, Renato Prudêncio da. Medicina, educação e psiquiatria para a infância: o Pavilhão-Escola Bourneville no início do século XX. Revista Latinoamericana de Psicopatologia Fundamental, São Paulo, v.12, n.1, p.195-208, março 2009; MULLER, Tânia Mara Pedro. A primeira escola especial para creanças anormaes no Distrito Federal: o Pavilhão Bourneville (1903-1920). Revista Brasileira de Educação Especial, São Paulo, v.6, n.1, 2000.

34 BARBOSA, L. Fernandes Figueira na pediatria brasileira, p.43.

35 BARBOSA, L. A função professoral de Nascimento Gurgel. Pediatria Prática. Revista mensal de clínica infantil e puericultura, v.l, fasc.Vl, p.4, agosto 1928. 
em 1928, e em seu lugar Luiz Barbosa assumiu o posto de catedrático de clínica de pediatria médica e higiene infantil. A morte de Nascimento Gurgel e a ascensão de Luiz Barbosa coincidiram com o falecimento de Fernandes Figueira, também em 1928.

Mesmo depois da fracassada a tentativa de assumir a cátedra por ocasião do concurso ocorrido em 1910, Fernandes Figueira manteve-se vinculado à FMRJ na condição de professor livre-docente. Como já vimos, a única prerrogativa do professor livre-docente era poder oferecer "cursos equiparados" aos do currículo do ensino oficial. Em 1911, Fernandes Figueira publicou em Brasil Médico sucinto relatório encaminhado ao diretor da FMRJ pelo qual prestava conta do curso de pediatria ministrado em parceria com o também livre-docente Mello Leitão. Evidentemente a realização desse curso de pediatria logo após o episódio do concurso tinha o sentido de revanche. O relatório assinala a "frequência notável de alunos" ao curso, a adoção de "ensino essencialmente prático, como exige as ciências de nosso tempo" e, sobretudo, destaca a ênfase conferida à semiótica infantil, matéria na qual Figueira já se tornara autoridade reconhecida. ${ }^{36}$

Como já se era tradição no Rio de Janeiro desde os tempos de Moncorvo de Figueiredo, o curso de pediatria oferecido por Fernandes Figueira também funcionou à margem da Faculdade de Medicina. No entanto, nesse caso, havia uma novidade importante. O curso estava anexado à Policlínica de Crianças, hospital infantil de caráter filantrópico formalmente vinculado à Santa Casa de Misericórdia. Demarcava-se então, no campo da pediatria, complicada relação institucional entre a FMRJ, entidades filantrópicas privadas (Policlínica Geral do Rio de Janeiro, Ipai e Policlínica de Botafogo) e Santa Casa de Misericórdia, responsável tanto pela Policlínica de Crianças como pelas enfermarias vinculadas às cátedras de clínica de pediatria médica e de higiene infantil e de clínica cirúrgica infantil e ortopédica. Embora a FMRJ fosse oficialmente responsável pelo ensino da pediatria na capital federal, na prática, as atividades pedagógicas de clínica pediátrica eram realizadas em entidades que estavam fora de seu alcance formal.

Mesmo não sendo os catedráticos, Fernandes Figueira e Luis Barbosa tornaram-se, cada ao seu modo, os expoentes do ensino e da clínica da pediatria no Rio de Janeiro durante as décadas de 1910 e 1920, bem como responsáveis pela organização de sistema de assistência à saúde da infância de caráter ao mesmo tempo público e filantrópico - afinal, o limite entre o público e o privado era, nessa época, muito tênue.

Também reconhecido como discípulo de Moncorvo de Figueiredo, Luiz Barbosa (1870-1949) iniciou sua carreira clínica na pediatria atuando como chefe de serviço dessa especialidade na Policlínica de Botafogo, entidade

36 FIGUEIRA, A. F. Relatório do curso de pediatria. Brasil Médico, ano XXV, n.44, p.448, 1911. 
filantrópica privada, de sua propriedade, inaugurada em 1899. Na condição de livre-docente da FMRJ promoveu cursos livres de pediatria "de caráter eminentemente prático", cujas aulas eram ministradas na 25ํㅡㄹ enfermaria da Santa Casa de Misericórdia - da qual o provedor o nomeara médicochefe em substituição ao ex-catedrático Barata Ribeiro - e no consultório da Policlínica de Botafogo. ${ }^{37}$

Em torno do ensino da pediatria tecia-se emaranhada rede de relações pessoais, políticas e institucionais que proporcionava a existência simultânea de vários cursos de pediatria oficiais e "equiparados". O mais curioso, porém, era o fato de os dois catedráticos de pediatria FMRJ não exercerem sua autoridade pedagógica sobre as enfermarias ou clínicas que efetivamente proporcionavam treinamento clínico aos estudantes e aos médicos recém-formados. Mesmo na Santa Casa de Misericórdia - em que tradicionalmente ocorria o treinamento clínico e cirúrgico dos estudantes da FMRJ - a Policlínica das Crianças e a 25a enfermaria de clínica de pediatria estavam sob o comando de Fernandes Figueira e Luiz Barbosa, respectivamente. A dicotomia entre a cátedra e a clínica foi peculiaridade da cultura institucional do ensino da pediatria no Rio de Janeiro.

A posse de Luiz Barbosa na cadeira de clínica de pediatria médica e higiene infantil, ocorrida em 1928, encerra simbolicamente essa fase de implantação do ensino da pediatria na FMRJ marcada por disputas pelo controle da autoridade científica. A lição inaugural intitulada $\mathrm{O}$ especialista em crianças, pronunciada na abertura do ano letivo de 1929, anunciava que a partir de então, pacificadas as disputas internas, os pediatras deveriam preocupar-se com a construção da identidade profissional.

O objetivo da explanação feita por Luiz Barbosa aos alunos do quinto ano do curso de medicina foi explicar as exigências técnicas da especialidade e enfatizar a importância da missão social do pediatra. A lição era clara. Diante do trágico quadro da mortalidade infantil, a dedicação à pediatria exigia do futuro médico a combinação de três papéis que deveriam ser exercidos com perícia e equilíbrio: "ora como higienista, ora como clínico e sempre como sociólogo a serviço dos mais nobres sentimentos cívicos". Nesse sentido, destacava-se o papel "sociológico" do pediatra, que deveria estar presente não só nas clínicas, enfermarias e ambulatórios, mas, sobretudo, "dentro dos lares e das coletividades infantis", promovendo pela "propaganda falada e escrita, pela difusão constante de ensinamentos de ordem prática"38 a profilaxia da infância e a educação das famílias (e também dos próprios médicos), a cujos preconceitos, ignorância e superstições

37 BARBOSA, L. Clínica de crianças: conferência inaugural, p.22-23.

38 BARBOSA, L. O especialista de crianças. Pediatria Prática. Revista mensal de clínica infantil e puericultura, v.ll, fasc.X, p.314, março 1930 
dever-se-ia atribuir a maioria dos problemas de saúde manifestados pelas crianças, sobretudo as das classes pobres.

Ao eleger o tema da alimentação (natural e artificial) como núcleo principal de ação do pediatra, Luiz Barbosa não apenas confirmava o paradigma dominante na pediatria da época como também reiterava a estratégia prioritária das instituições de assistência à infância em atividade no Rio de Janeiro desde 1900. Essas instituições dedicavam à questão da alimentação a maior parte de seus esforços, criando formas de incentivar e valorizar o aleitamento materno, promovendo a distribuição de leite de vaca "pasteurizado", combatendo ou "higienizando" o serviço das amas de leite, reclamando a inspeção sanitária do leite vendido na cidade. Creditava-se à adoção de técnicas modernas de alimentação efeito positivo no recuo das taxas de mortalidade infantil, sobretudo em relações às perturbações digestivas e nutritivas da primeira idade, consideradas as principais causadoras de óbitos.

\section{Luiz Barbosa e a Policlínica de Botafogo}

A Policlínica de Botafogo foi criada por Luiz Barbosa em finais de 1899 e iniciou suas atividades em junho de 1900 visando ao atendimento de crianças. Sua marca mais forte era a atuação paroquial, restrita aos moradores de Botafogo e adjacências. Instituição privada, era mantida por seus protetores, todos moradores daquele bairro. Seus principais benfeitores eram o conselheiro Catta-Preta, Eugenio José de Almeida, Eduardo P. Guinle, Candido Gaffrée, senador Antonio Azeredo, John Gregory e Oswaldo Cruz.

Desse grupo, vale ressaltar a relação que existiu entre a família Guinle e essa instituição: Luiz Barbosa era o médico particular de Eduardo P. Guinle, e Eduardo e sua esposa, Guilhermina, foram os grandes benfeitores da instituição, a ponto de, por ocasião da inauguração da sede da Policlínica, em 1922, foi proposta a criação de um Instituto de Puericultura que receberia o nome de Instituto Guinle-Gaffrée, em homenagem a seus dois beneméritos já falecidos. E, em 1925, após a morte de Guilhermina, foi proposto que a seção de puericultura passasse a ser denominada Berçário Maternal e Infantil Guilhermina Guinle, em homenagem a sua atuação em prol da instituição. ${ }^{39}$

A preocupação com a infância foi reforçada com a abertura, em 1910, do Serviço de Doenças de Crianças, que contou com nomes que se tornariam importantes na especialidade: além do próprio Luiz Barbosa, Azarias de Andrade Carvalho, Jacob Renato Woiski, Álvaro Aguiar e Rinaldo de

39 Não há indicação que tenha se efetivado realmente a criação do Instituto Guinle-Gaffrée, mas é certo que o nome de Guilhermina Guinle batizou o Instituto de Puericultura - Beneficiário Guilhermina Guinle, como se verá mais adiante. 
Lamare. Para esse serviço da Policlínica, Luiz Barbosa levou, na década de 1930, a cátedra de pediatria da Faculdade de Medicina do Rio de Janeiro, vínculo mantido até 1940.

Luiz Barbosa diferencia-se de outros dois pediatras seus contemporâneos, Arthur Moncorvo Filho e Antônio Fernandes Figueira, por duas razões: a primeira por ter sido diretor da Saúde Pública do Distrito Federal no início do século XX e, como tal, responsável pela criação do Pronto-Socorro Municipal em 1907 - atual Hospital Municipal Souza Aguiar. Em segundo lugar, por ter sido professor da Faculdade de Medicina do Rio de Janeiro, tendo assumido a cátedra de pediatria em janeiro de 1928. Luiz Barbosa também participou ativamente de todas as discussões acerca da construção do Hospital de Clínicas da Faculdade de Medicina, ${ }^{40}$ o que reforça ainda mais seu caráter de gestor da saúde pública.

A Policlínica de Botafogo caracterizou-se por forte articulação com a assistência pública municipal - o que a singulariza em comparação com - Ipai ou a Policlínica das Crianças. Além das intervenções na época da epidemia de gripe espanhola, em 1918, comum a todas as instituições filantrópicas do período, vale ressaltar que a partir de 1921 firmou convênio com o Departamento Nacional de Saúde Pública (DNSP) para a organização de um Ambulatório de Profilaxia contra a Lepra e as Doenças Venéreas. Esse convênio, além de reforçar o vínculo de Luiz Barbosa com a organização da assistência pública, chama atenção para mais uma ligação com a família Guinle. Os ambulatórios da Inspetoria de Profilaxia da Lepra e das Doenças Venéreas foram construídos/equipados pela Fundação Gaffrée e Guinle, criada por Guilherme Guinle, com fundo de todos os irmãos Guinle, filhos de Eduardo e Guilhermina Guinle. ${ }^{41}$ A opção por instalar um dos ambulatórios antivenéreos na Policlínica de Botafogo não foi aleatória.

Outro ponto, já referido, é a ligação de Luiz Barbosa com a cátedra de pediatria da Faculdade de Medicina. Como já salientado, as enfermarias do Hospital da Misericórdia eram insuficientes e impróprias, pois até 1909, quando é criada a Policlínica das Crianças, adultos e crianças compartilhavam o mesmo espaço físico no Hospital da Misericórdia. Como se verá a seguir, a criação da Policlínica das Crianças não só separou as duas clientelas como garantiu espaço para as aulas práticas de pediatria, até a criação do Hospital S. Zaccharias, em 1914, que passou a exercer as funções de espaço da clínica de pediatria da Faculdade de Medicina. Vale ressaltar que ambas as instituições eram mantidas pela Irmandade da Misericórdia.

Luiz Barbosa era chefe da 11a enfermaria pediátrica do Hospital São Francisco de Assis, mantido pelo DNSP, e diretor-fundador da Policlínica de Botafogo. É para essa segunda instituição que ele irá transferir as aulas

40 SANGLARD, Gisele. A Primeira República e a constituição de uma rede hospitalar no Rio de Janeiro.

41 SANGLARD, Gisele. Entre os salões e o laboratório: Guilherme Guinle, a saúde e a ciência no Rio de Janeiro. 
práticas de pediatria. Alguns pontos devem ser salientados: desde 1918 a Faculdade de Medicina estava instalada na Praia Vermelha, no prédio construído para abrigá-la, e a Policlínica de Botafogo inaugura sua sede definitiva em 1922 na Praia da Saudade. O deslocamento entre ambos os edifícios não era muito longo, o que facilitava ou aproximava as aulas teóricas da prática..$^{42} \mathrm{O}$ próprio Luiz Barbosa, em conferência realizada em 1930, por ocasião da inauguração das novas instalações da 11a Enfermaria do Hospital São Francisco de Assis, afirma que a opção pela Policlínica de Botafogo justificava-se pela inexistência de instalações adequadas no Hospital São Francisco de Assis ${ }^{43}$ e, podemos acrescentar, nas outras instituições voltadas para a assistência à infância.

Em seu discurso de posse na cátedra de pediatria, Luiz Barbosa é claro ao afirmar que conseguira pôr em prática ideias que há muito defendia. Desde o início do século XX ele já advogava a necessidade de reforma da assistência no Distrito Federal. Em 1908 ele apresentou, no livro Serviços de assistência no Rio de Janeiro, como deveria ser organizada a assistência pública pela prefeitura. Nessa obra, defendia a aplicação, na capital, de um sistema de socorro similar ao de Buenos Aires, que dividia a cidade em distritos de atuação dos socorros, sendo as ambulâncias dirigidas por acadêmicos de medicina. A comparação entre as duas capitais sulamericanas era bem desfavorável ao Rio de Janeiro, cujo transporte de doentes e feridos era realizado em padiolas emprestadas ou em veículos da Assistência Policial e, na maior parte das vezes, sem exame médico. E sugeria a necessidade de acordo com o governo federal para instalar seus postos nas delegacias de saúde e o aproveitamento das policlínicas como recurso complementar aos socorros de urgência. Contudo, só ao assumir a cátedra de pediatria, em 1928, Luiz Barbosa consegue colocar a Policlínica de Botafogo no cerne da assistência pública e do ensino da pediatria; se não toda a policlínica, pelo menos seu Instituto de Puericultura - Beneficiário Guilhermina Guinle.

Enfim, no que tange à relação de Luiz Barbosa com a Policlínica de Botafogo, vemos uma centralização das ações na liderança desse médico, tanto no que concerne à criação da instituição quanto na gestão da saúde pública do Distrito Federal. Por outro lado, ele foi muito eficaz ao conseguir o apoio da elite carioca moradora do bairro nobre de Botafogo - provavelmente, muitos membros dessa elite faziam parte de sua clientela particular, como, por exemplo, Eduardo P. Guinle.

42 Uma das discussões acerca da localização do Hospital de Clínicas da Faculdade de Medicina, em 1926, era justamente a distância que ele ficaria do prédio da Faculdade. Havia um grupo de médicos que advogava a construção do hospital próximo à faculdade. Ver SANGLARD, Gisele. A Primeira República e a constituição de uma rede hospitalar no Rio de Janeiro.

43 BARBOSA, L. Proteção da criança pelo ensino. Pediatria Prática. Revista mensal de clínica infantil e puericultura, v.3, fasc.VI, p.43-53, agosto 1930. 
O envolvimento da família Guinle com a infância, notadamente, o da matriarca Guilhermina Guinle, vinha de longa data. Além da tradicional caridade na Irmandade da Misericórdia (pai e filho foram irmãos da Misericórdia), vemos Eduardo P. Guinle como grande benemérito da Policlínica de Botafogo e do Ipai; Guilhermina Guinle como grande benemérita da Policlínica de Botafogo, do Ipai, da Liga Brasileira contra a Tuberculose e da Fundação Gaffrée e Guinle; e o filho deles, Guilherme, colaborando com a Fundação Gaffrée e Guinle, a Liga Brasileira contra a Tuberculose, a Fundação Oswaldo Cruz (1922-1936), o Instituto Arnaldo Vieira de Carvalho, entre outras instituições. Guilhermina Guinle foi grande benemérita do Educandário Romão Duarte, antiga Casa dos Expostos, da Misericórdia carioca, tendo a gratidão expressa no retrato de corpo inteiro no hall de entrada do Hospital Geral da Misericórdia do Rio de Janeiro; bem como através das notícias fúnebres sobre sua morte logo publicadas nos principais periódicos cariocas. Vale ressaltar que seu cortejo fúnebre foi acompanhado pela banda de música da Casa dos Expostos em honra a sua memória. ${ }^{44}$

A relação da Policlínica de Botafogo com a elite carioca aponta para o papel fundamental de Luiz Barbosa na condução da divulgação de seu trabalho, bem como do prestígio político, profissional e social que ele conquistou e capitalizou para a instituição que criara. Nesse caso, a atuação extramédica de Luiz Barbosa foi capital para a visibilidade da Policlínica de Botafogo.

\section{Fernandes Figueira e a Policlínica de Crianças da Santa Casa da Misericórdia do Rio de Janeiro ${ }^{45}$}

A Policlínica de Crianças foi criada graças à ação benemerente de José Carlos Rodrigues e à concordância da Misericórdia carioca. Sua movimentação em prol desse projeto inicia-se com a aquisição de uma chácara na rua Marquês de Abrantes. Contudo, a necessidade de dar outro espaço à Casa dos Expostos, fez com que a chácara fosse destinada a essa instituição. Entre 1905 e 1907 foram adquiridos os terrenos em São Cristóvão, em que se localizaria o Hospital de Crianças.

A criação da Policlínica de Crianças contou com dois grandes beneméritos: o próprio José Carlos Rodrigues, diretor do Jornal do Commercio, e do comerciante suíço Albert Bach, que legou, em 1906, seus bens a essa obra de caridade. Já para a criação do Internato do Hospital das Crianças

\footnotetext{
44 SANGLARD, Gisele. Cultura, sociedade e saúde no Rio de Janeiro durante a Primeira República. In MARTINS, W. e SANGLARD, Gisela. (orgs.) História cultural: ensaios sobre linguagens, identidades e práticas de poder. Rio de Janeiro: Editora Apicuri, 2010. (no prelo).

45 Nesse tema contamos com a colaboração da bolsista Bárbara Damasco da Silva (Pibic/Fiocruz).
} 
foi lançada uma lista de subscrição pública da qual participaram 77 firmas comerciais, no total de 90 inscritos.

A inauguração do prédio, em 8 de maio de 1909, foi realizada pelo provedor, Miguel de Carvalho, contando com a presença do presidente da República, Afonso Pena. O projeto da edificação foi realizado por Antônio Jannuzzi, seguindo o plano proposto por J.C. Rodrigues assessorado pelo médico e acadêmico Manoel de Oliveira. O hospital mantinha espaços para balnearioterapia, farmácia, leiteria (leite esterilizado), cômodos para empregados, consultórios (clínica médica, cirurgia, curativos, odontologia, moléstias de pele, moléstias especiais da gravidez, olhos, otorrinolaringologia), gabinetes (químico-bacteriológico, eletroterápico), espaço para o diretor, mordomo e para as irmãs de caridade; além do salão de honra e conferências. Para seu idealizador, a "construção e disposição do edifício da Policlínica representa a última palavra em obras deste gênero em qualquer país do mundo". ${ }^{46}$

A presença majoritária de comerciantes aponta para a manipulação do capital político de José Carlos Rodrigues a favor de sua obra de caridade. Refiro-me primordialmente a sua troca de correspondência com a Associação dos Empregados no Comércio do Rio de Janeiro. A leitura dessas missivas ${ }^{47}$ permite aferir que José Carlos Rodrigues defendeu os interesses dos comerciantes cariocas nas páginas do Jornal do Commercio, fato que ensejou o reconhecimento da classe, na forma de um presente. Em vez, porém, de aceitar para si a benevolência ofertada, J. C. Rodrigues a transfere para a instituição que fundara. O resultado é uma listagem de 77 empresas que doam entre $100 \$ 000$ e $500 \$ 000$, e de alguns particulares, residentes sobretudo em Paris, que doam quantias diversas. Ainda houve duas remessas feitas através do Jornal do Commercio.

No que tange ao círculo próximo de Fernandes Figueira, uma análise do grupo presente no Hospital/Policlínica das Crianças aponta para nomes ligados a Manguinhos, muitos egressos dos cursos de aplicação do Instituto Oswaldo $\mathrm{Cruz}^{48}$ - lócus por excelência desde 1903 da formação de microbiologistas pasteurianos no Brasil -, caracterizando a ligação do próprio Fernandes Figueira com Manguinhos. Desse grupo sobressaem Eduardo Rabello, chefe do Serviço de Dermatologia; Gomes de Faria, chefe do Serviço de Bacteriologia; e João Marinho, chefe do Serviço de Otorrinolaringologia. Deve-se ressaltar que Antônio Fernandes Figueira já

46 IHGB. Coleção José Carlos Rodrigues, Notação: 585-1

47 IHGB. Coleção José Carlos Rodrigues.

48 O Curso de Aplicação do Instituto Oswaldo Cruz começou a ser organizado em 1903 por Henrique Rocha Lima. Eram cursos experimentais voltados para o ensino de bacteriologia, parasitologia, anatomia e histologia patológicas. O público-alvo era formado primordialmente de estudantes de medicina que, desde 1901, frequentavam os laboratórios do Instituto a fim de desenvolver suas teses de doutoramento, e de profissionais já formados. BENCHIMOL, Jaime Larry. (coord.) Manguinhos do sonho à vida: a ciência na Belle Époque. Rio de Janeiro: Casa de Oswaldo Cruz/Fiocruz; 1990. 
gozava de prestígio profissional - era membro da Academia Nacional de Medicina desde 1903.

Esse grupo também estará vinculado às políticas públicas traçadas por Carlos Chagas no Departamento Nacional de Saúde Pública (DNSP), criado em 1919 para atuar no Distrito Federal e no território do Acre, e, através de convênios, em todo território nacional. Fernandes Figueira foi o responsável pelo programa da Inspetoria de Higiene Infantil e, em 1924, foi alçado a diretor do recém-criado Hospital-Abrigo Arthur Bernardes, voltado para o atendimento da puericultura intra e extrauterina.

Eduardo Rabello era muito próximo a Carlos Chagas tanto por laços de amizade quanto profissionais, o que lhe permitiu a gestão das políticas públicas de controle e profilaxia das doenças dermatológicas.

José Gomes de Faria foi o único que pertenceu ao quadro permanente de biologistas (pesquisadores) do Instituto Oswaldo Cruz.

Por fim, João Marinho - o menos conhecido deles - assumiu a cátedra de otorrinolaringologia na Faculdade de Medicina, sucedendo a Hilário de Gouveia. É indicado por Carlos Chagas para ser o primeiro diretor da Assistência Hospitalar - órgão criado no final da gestão de Arthur Bernardes (1926) e efetivado já com Washington Luís, que tinha como objetivo gerenciar os hospitais públicos ${ }^{49}$ no Distrito Federal, bem como ser o responsável pela construção do Hospital de Clínicas Arthur Bernardes da Faculdade de Medicina do Rio de Janeiro, que seria tanto o lugar da prática médica quanto da assistência pública.

A presença de José Carlos Rodrigues como filantropo da entidade e diretor do Jornal do Commercio fez com que a instituição tivesse bastante divulgação nesse veículo de imprensa, e o caráter oficial que o Jornal do Commercio ainda tinha nesse período desempenhou papel importante na organização dos filantropos - afinal, como já ressaltado, o grupo surgiu a partir de uma defesa que José Carlos Rodrigues levou a cabo nas páginas do periódico acerca da taxa do Porto.

Em 1916, dois anos após a inauguração do Hospital São Zaccharias - o segundo da Irmandade da Misericórdia voltado para a infância, José Carlos Rodrigues publica no Jornal do Commercio um relatório sobre o funcionamento do hospital, transformado em folheto em 1920. Além de mencionar sua fundação, descrever o prédio e os serviços, a matéria enaltece quatro personagens: os filantropos Alberto Barth, Miguel de Carvalho, provedor da Misericórdia, Fernandes Figueira, diretor responsável pelo hospital, e, notadamente, José Carlos Rodrigues. A matéria ressalta que, nos sete primeiros anos a instituição ministrou gratuitamente cerca de um milhão

49 Eram eles: o Hospital São Sebastião (1889, para doenças ifectocontagiosas); o Hospício Nacional de Alienados; 0 Hospital São Francisco de Assis (1922, geral); o Hospital Paula Cândido (doenças infectocontagiosas); a Colônia Juliano Moreira (1914, doenças mentais) e a Colônia de Curupaity ( hanseníase). 
de auxílios, sob as formas diversas de consultas, curativos, receitas, etc. E que nos quatro anos subsequentes houve aumento da média diária de atendimento (chegando a 341 crianças por dia).

Chama também atenção para as visitas domiciliárias - que não se limitam ao tratamento dos enfermos graves, mas registram também em boletim apropriado as condições higiênicas, condições de alimentação e da residência dos socorridos - e o funcionamento do consultório de higiene infantil, em que eram atendidos os lactentes e fornecido, ou aconselhado, o alimento oportuno, isto é, o leite materno. Nesse consultório as crianças eram examinadas semanalmente, o que incluía a pesagem e outros procedimentos para acompanhamento de seu desenvolvimento.

Por fim a matéria deixa claro que a instituição não tinha apoio dos órgãos públicos, quer seja na prefeitura do Distrito Federal, quer do governo federal, nem mesmo no que tange à isenção de impostos para a importação de material ou para a receita de loterias, prática comum à época.
A Policlínica deve a sua útil existência ao seu doador, o Sr. Dr. José Carlos Rodri- gues, á benemérita instituição da S. C. da Misericórdia, ao fallecido Sr. A. Bath que the deixou tão principesco legado e a outros benfeitores, muito poucos, infelizmente que the têm dado para allivio das crianças pobres, suas esmolas, detacando-se entre elles o engenheiro Arthur Alvim de cujo magnífico legado, se apurou a somma de setenta e cinco contos de réis para o fundo de manu- tenção do estabelecimento. Não menos grata é a administração por favores de sommas menores recebidas de varias pessoas entre as quaes se salientam as Sras. Baronesa do Bomfim e sua digna filha D. Jeronyma de Mesquista. ${ }^{50}$

Para finalizar a análise da relação que se estabeleceu entre José Carlos Rodrigues e Antônio Fernandes Figueira podemos afirmar que o Hospital de Crianças foi realmente um projeto de ambos os personagens: o filantropo deu-lhe a forma física, os equipamentos e sua manutenção; e o médico, o respaldo profissional. Assim, sua realização traduz o capital social de cada um deles, tal qual já demonstrado. Por outro lado, se sua manutenção nos aponta para a tradicional caridade realizada pela Misericórdia, seu desenvolvimento nos permite questionar se as relações de José Carlos Rodrigues com o provedor Miguel de Carvalho e de Fernandes Figueira com a Faculdade de Medicina do Rio de Janeiro não influenciaram os destinos da instituição - fechada na década de 1940 por questões financeiras.

50 A POLICLÍNICA DE CRIANÇAS POBRES da Santa Casa da Misericórdia fundada e doada pelo Dr. José Carlos Rodrigues e inaugurada pelo presidente Affonso Penna a 8 de maio de 1909 - retrospecto de 11 anos de serviços sob a direção do Dr. Fernandes Figueira. Rio de Janeiro: Typ. do Jornal do Commercio, 1920 (Col. Rui Barbosa), com fotos 


\section{Conclusão}

Ao longo deste artigo ressaltamos a relação umbilical entre a institucionalização da pediatria e a criação de instituições de assistência à infância seguindo roteiro no qual se afirmava o papel de protagonistas dos médicos enquanto especialistas e se ressignificava o papel do benemérito na prestação de serviços de proteção e auxílio. Atuando em várias frentes, os médicos e filantropos priorizavam o combate à mortalidade infantil. Para isso, além de apoiarem a realização de campanhas de higiene e de saúde pública, criaram instituições, quase sempre de caráter filantrópico, nas quais promoveram ações de assistência à infância, com destaque para educação das mulheres visando ao exercício "correto" da maternidade, sobretudo em temas relacionados aos cuidados com a saúde física e mental das crianças. As mesmas instituições também serviram ao propósito de estabelecer a pediatria e a puericultura como áreas médicas especializadas na saúde da infância.

Em síntese, as ações científicas foram motivadas, em última instância, pela ideia de que a ausência de políticas públicas que visassem corrigir os "maus hábitos" típicos da cultura das famílias (sobretudo das famílias do vasto setor das classes trabalhadoras urbanas) e as práticas pré-científicas vigentes nas instituições escolares, hospitalares, asilares e correcionais condenavam a infância brasileiras à doença. E, no tempo em que o liberalismo ainda dominava as práticas assistências, o concurso da filantropia tornou-se fundamental para que as ideias defendidas por esses médicos fossem postas em prática. 


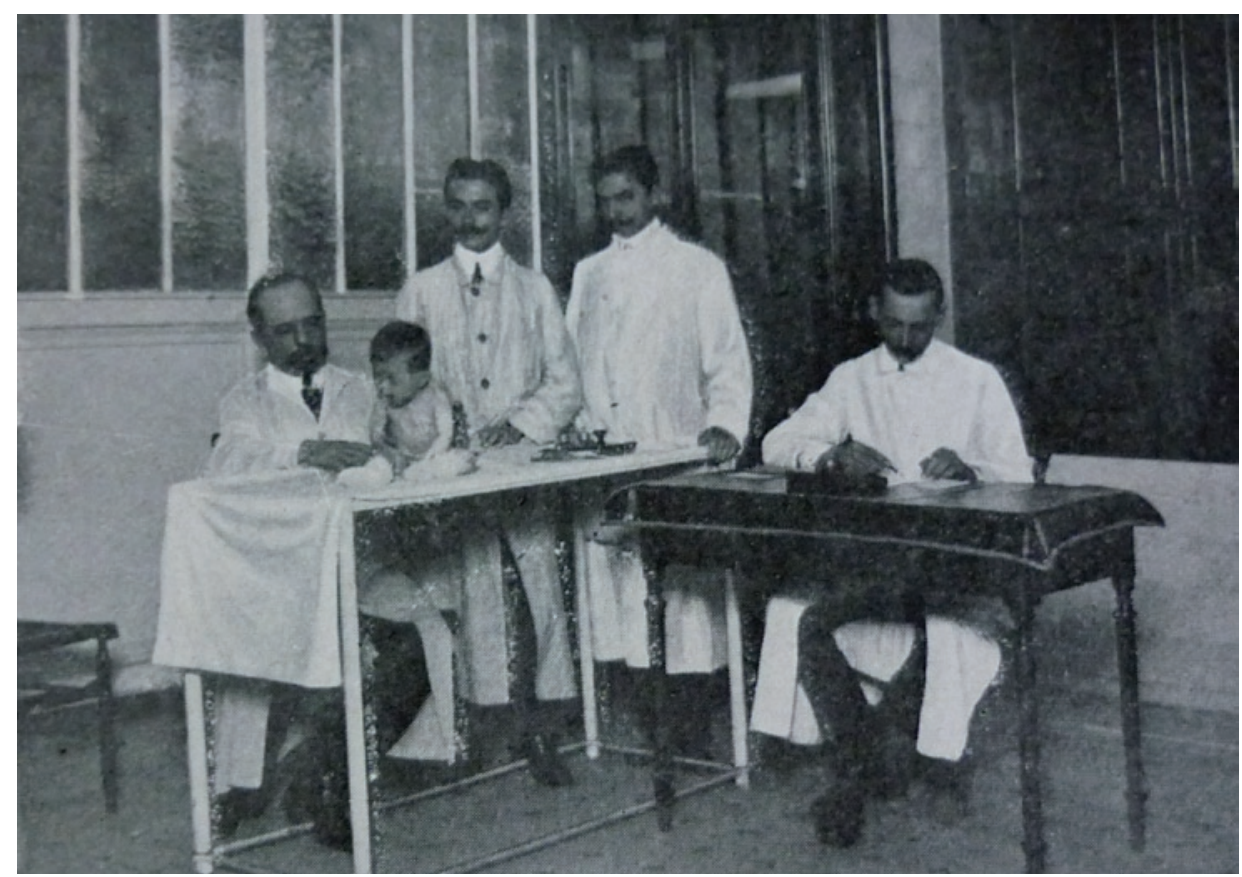

Imagem 1: Um consultório de moléstias gerais: o Dr. Fernandes Figueira

Fonte: A Policlínica de Crianças Pobres..., 1916. Acervo Casa de Rui Barbosa

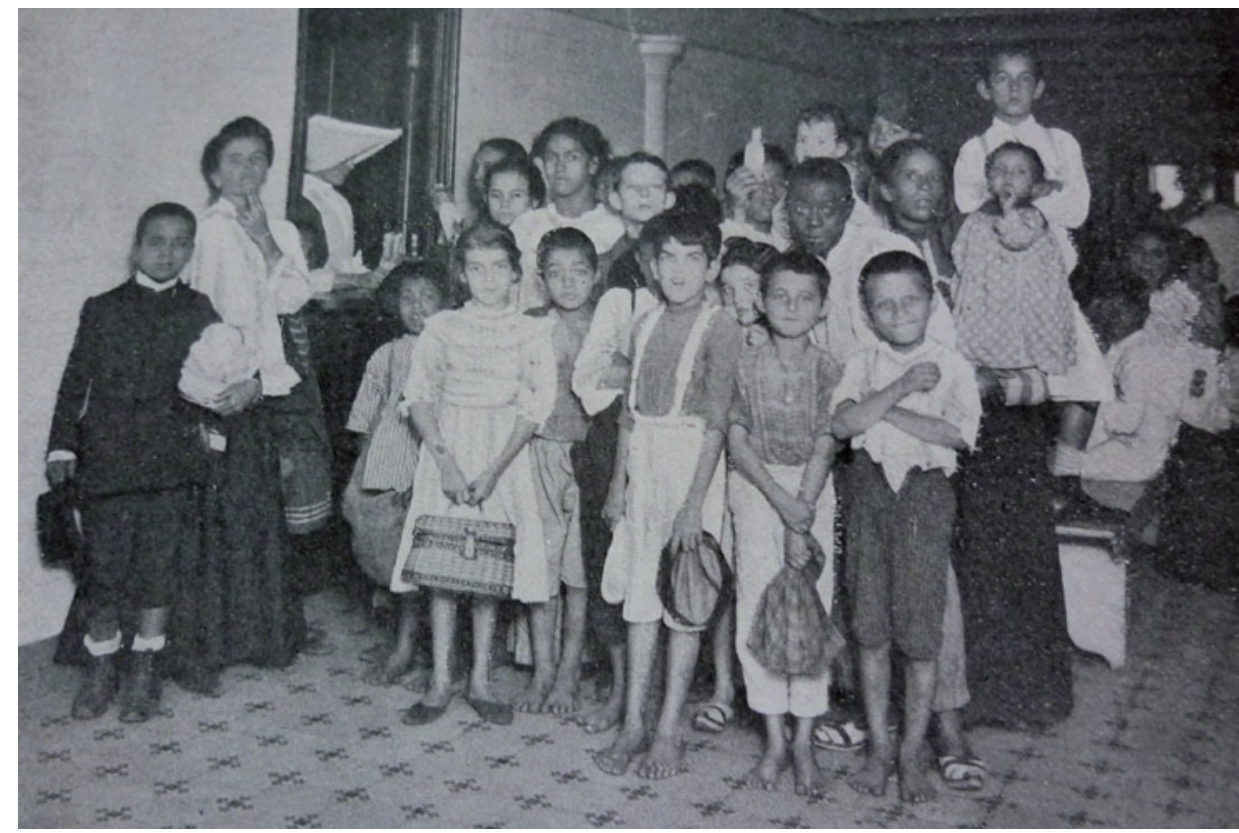

Imagem 2: Esperando o leite

Fonte: A Policlínica de Crianças Pobres..., 1916. Acervo Casa de Rui Barbosa 